\title{
Empire, emotion, exchange: (dis)orienting encounters of/with post-9/11 US cultural diplomacy
}

\author{
Laura Mills \\ School of International Relations, University of St Andrews, St Andrews, UK \\ ljm33@st-andrews.ac.uk
}

\begin{abstract}
This article disentangles how empire, emotion and exchange intersect and work to orient and disorient processes of identity formation within post-9/11 US cultural diplomacy. Focusing on everyday cultural exchange practices, it challenges the particular cosmopolitanism embedded in these programmes that hinges upon the affective and the colonial. It reflects on how this entanglement of empire, emotion and exchange operates through modes of governmentality that produce energized, more governable subjects and masks such operations of power. Analysing one particular exchange - YES - this article disorients colonial logics of subjectification by exploring affective exchange encounters that are always already (dis)orienting. It then serves as a disorienting encounter with cultural diplomacy through four provocations, illustrating how empire is (always) (dis)orientating, can (dis)orient, can be disoriented, and must undergo disorientation. First, post-9/11 US cultural diplomacy and its logic of cosmopolitanism suggest empire is always (dis)orientating via its manifestation in 'unusual' sites; while exchange programmes' onus on celebrating difference appears to conflict with 'where' empire 'normally' orients itself, as post/decolonial scholarship reveals, it is in the seemingly benign/unquestionable where empire does its work most profoundly. Second, the entanglement of emotion, empire and exchange can (dis)orient exchange subjects through how they are governed to perform and oscillate between ever-shifting 'ideal' subjectivities (familiar national/ cosmopolitan global/enterprising neoliberal). Third, tracing colonial echoes and spectres in these exchanges reveals empire as disoriented, as that which is analytically 'less conventional'. An arguably 'conventional' analysis oriented around a neo-colonial logic and an imperialistic 'America' while seductive in its simplicity obscures the governmental and performative complexities operating within these programmes. Finally, disorientation enables empire to be challenged and disrupted, opening up possibilities for post-9/11 US cultural diplomacy, and the self-Other relations comprising it, to be reimagined. In short, this paper's analytical disorientation can lead to a reorientation of cultural diplomacy.
\end{abstract}

KEYWORDS Cultural diplomacy; disorientation; empire; emotion; exchange

In the aftermath of the 11 September 2001 attacks, cultural diplomacy came under the spotlight. Claims abounded from practitioners and academics, policymakers and the media that the ball had seemingly been dropped on US cultural diplomacy after the Cold War and that its revitalization was essential. In particular, much onus was placed on an expansion of cultural exchange programmes, lauded for their ability to cultivate cross-cultural understanding through people-to-people connections. Since then, myriad cultural exchange programmes have been launched by the US State Department, with many in fact positioned as being 'in response to' the 11 September 2001 attacks. One such exchange is the Youth Exchange and Study programme (YES). This academic exchange programme has its roots in the Cultural Bridges Act of 2002 which seeks 'to promote the national security of the United States through international educational and cultural exchange programs between the United States and the Islamic world.' Providing scholarships for secondary school students from 'countries with significant Muslim populations' to spend an academic year in the US, with scholarships also available for US high school students to study in selected YES countries through YES Abroad, YES is promoted as 'seek[ing] to present a positive response to tragic world events by bringing communities together through links of close personal ties' (AFS-USA YES Team 2010, p. 5). Such moves do not signify a 'new' cultural diplomacy (cf. Melissen 2007); cultural exchange programming as promoting cross-cultural understanding has a long history, while the Cold War echo in these specific programmes' framing is unquestionable. But with programmes' overt designation as 'a response to the events of 11 September 2001' (YES Programs n.d.), there is a need to analyse these programmes in their particularity. Taking YES as its empirical focus, this paper turns a more critical lens on US cultural diplomacy, troubling these under- standings of cultural exchange as a benign and virtuous practice that merely brings people together to celebrate and learn from their differences. It does so by examining what often goes unnoticed or not deemed worthy of analysis - the everyday of these exchanges. I argue that it is in the everyday and the cultural that the global is co-constituted. Analysing the specificities

$1 \mid 17$ 
of these programmes reveals that any 'newness' of cultural diplomacy stems from the intricacies of the social and political fields in which they circulate. My use of the prefix 'post-9/11' is therefore to play on and subvert such terms and their representations as 'common sense' imaginings of the world. Focusing on everyday cultural exchange practices and the 'ordinary' individuals who are exchange participants enables one therefore to reveal the particular global power relations of post-9/11 US cultural diplomacy in all their complexity and messiness.

This article draws from and builds on the arguments of a larger project that analyses the everyday of these exchanges through both 'official' and less 'traditional' sites - from programme documents, websites and social media pages to images, films and blogs to ethnographic encounters and interviews with both 'ordinary' citizens and exchange practitioners - to interrogate how exchange participants are produced as political subjects and how their performances of particular identities partake in a global imaginary manifested in US cultural diplomacy programmes (Mills forthcoming). When one begins to examine the quotidian specificities of these exchanges and how everyday citizens such as high school students are encouraged to enact their daily exchange lives, one is struck by how post-9/11 US cultural diplomacy is oriented around/towards a particular cosmopolitanism. This is a very main- stream account of cosmopolitanism rooted in a humanism that seemingly advocates our shared humanity by virtue of our differences. In exchange encounters, this cosmopolitanism urges exchange participants to perform themselves as (often conflicting) familiar national and cosmopolitan global identities and to vacillate effortlessly between the two via certain skills manifested in the production and enactment of an enterprising neoliberal subjectivity. With its emphasis on 'two-way exchange', 'common values' and 'mutual understanding', this cosmopolitanism positions itself as universal, equal and open to all; but close examination of everyday exchange practices reveals it to be marked by particularities, asymmetries and exclusions that can essentialise, exoticise and Other. These violences are, of course, often not enacted in an overt or brash manner; like many colonial endeavours, they locate and (re)produce themselves in the ordinary, mundane, banal. Exploring the every- day sites, practices and performances that comprise post9/11 US cultural diplomacy thus also reveals how exchange encounters are highly affective, additionally imbued with a series of incitements and rewards that encourage exchange participants' performative enactment of these particular identities. This cosmopolitanism therefore also galvanises and incentivises exchange participants. Cultural exchanges therefore mobilize different cosmopolitan logics which, through certain governmental techniques, simultaneously enable and constrain, energize and regulate participants through their pro- duction of ideal subjectivities. In the case of YES, a cosmopolitan logic of tolerance encourages YES participants to perform national, global and neoliberal identities that appear to erode the binary of 'us' and 'them', 'America' and 'Muslim world', and procure a new tolerant - and competent - global citizenry. Interrogating this cosmopolitan logic of tolerance and the performativities and governmentalities it mobilizes reveals how participants' performance of these subjectivities always depends upon the careful ordering of conducts, management of difference, and denial of certain behaviours and identities. Far from benign, cultural exchanges suture participants' everyday lives - their quotidian behaviours, choices and desires - into wider US foreign policy objectives to enact a global imaginary that secures US power and privilege.

This article therefore contends that a close examination of the specificities of these cultural exchange programmes through performativity and governmentality also highlights how the particular cosmopolitanism embedded in these exchanges hinges upon, intersects with and co-constitutes the affective and the colonial. This article is therefore intrigued by how within these cosmopolitan logics - and the ideal identity performances they impel - nestles an entanglement of empire, emotion and exchange that manifests in these cultural diplomacy programmes' everyday relations, mundane practices and human (inter)actions. Exchange programmes like YES have received surprisingly little academic attention meaning this entanglement and its effects continue to be perpetuated without question. A logic of (dis)orientation enables this entanglement to be prized apart, this cosmopolitanism to be challenged and the global imaginary they bolster to be interrogated. Drawing upon critical understandings of performativity, governmentality and (dis)orientation, this article disentangles how empire, emotion and exchange intersect and work to orient and disorient processes of identity formation within post-9/11 US cultural diplomacy. It reflects on how this entanglement of empire, emotion and exchange operates through modes of governmentality that produce energized, more governable subjects and realms of performativity that can also lead to moments of 
resistance while masking such operations of power. This article thereby disorients colonial logics of subjectification through its exploration of affective exchange encounters that are always already (dis)orienting. By exploring the everyday of YES before, during, after and beyond the exchange, the article then serves as a disorienting encounter with cultural diplomacy through four provocations, illustrating how empire is (always) (dis)orientating, can (dis)orient, can be disoriented, and must undergo disorientation.

\section{Disentangling emotion, empire and exchange through the everyday}

Much analysis of cultural diplomacy resigns the cultural and the everyday to depoliticized spheres and therefore fails to acknowledge or analyse their centrality to the production and practice of global politics. Arguing that it is in the everyday and the cultural that the global is situated and produced, this article examines the micropolitics of YES - through a (digital) ethnography of YES sites, close interrogation of programme materials that direct participants' conduct, and analysis of their subsequent identity performances in their everyday exchange lives - to reveal how post-9/11 US cultural diplomacy is implicated in global power relations that enact colonial, geopolitical, cosmopolitan and neoliberal imaginaries. Governmentality is crucial to such an analysis for it enables an interrogation of how power operates and is experienced in everyday life and the annexation of these operations of power by global phenomena (Foucault 2008, pp. 30-1). Encouraging an analysis that probes and illuminates the particularities and specificities of exchange programmes, governmentality enables an examination of the various ways that the ordinary individuals comprising these exchanges are moulded, guided and directed to perform themselves as ideal subjects or resist and counter such power relations. Exploring YES's everyday practices and performances therefore reveals how the entanglement of emotion, empire and exchange manifests in post-9/11 US cultural diplomacy via various performativities and governmentalities that shape, manage and govern YES subjects. With YES students positioned as 'cultural ambassadors', who not only live with US host families and attend high schools but also 'engage in activities to learn about American society and values, acquire leadership skills, and help educate Americans about their countries and cultures' (YES Programs n.d.), the everyday of YES proves to be a rich site of enquiry. Adding (dis)orientation to the mix then enables a troubling of its underlying cosmopolitanism (in the case of YES, a cosmopolitan logic of tolerance) which is continually interrupted by colonial legacies that pervade and intersect exchange programmes' everyday specificities and affective encounters. As Wendy Brown (2006) illustrates, tolerance is always 'a discourse of power and a practice of governmentality' that can hinge upon hierarchical colonial power relations, including a civilizational discourse (i.e. it is 'primitive' to be tolerated, a discourse rarely turned inwardly). YES' cosmopolitan logic of tolerance and its co-constitutive identities therefore require politicization to reveal how tolerance is always a practice of Othering, demarcating what type of difference and which identity performances are tolerable/intolerable; indeed, the ideal YES conduct requires a limited, nonthreatening difference for its goal of intercultural learning to be met.

To interrogate the everyday politics of this entanglement of empire, emotion and exchange this article brings performativity and governmentality into conversation with (dis)orientation, most notably through the work of Butler, Foucault and Ahmed (and the literatures they have inspired), in order to 'think with' these scholars through a diffractive methodology (Barad 2007). That is, through diffractively reading this scholarship's insights 'through one another', new insights are in turn built that results in an entanglement - of 'respectful, detailed, ethical engagement' - of its own. As Barad affirms, 'diffractive readings bring inventive provocations' (Dolphijn and van der Tuin 2012, p. 50). Such provocations are key to this article's aims. So how do empire, emotion and exchange become entangled and, indeed, then disentangled? How can conversations between performativity, governmentality and (dis)orientation enable such (dis)entanglement?

In the case of post-9/11 US cultural diplomacy, exchange as cross-cultural encounter is oriented around highly prescribed conducts and identities - familiar national, cosmopolitan global, enterprising neoliberal. Performativity reveals how exchange participants' identities are not 'natural', pre-given nor stable; rather, they are always subjects in the process of becoming (Butler 1988, 1990). Performativity as the operation of discourse that enacts what it names involves a series of performances, that is, discursive practices that (re)produce over and again a series of effects. The subjects of cultural exchanges are therefore not fixed ontological beings but the 'effects of prac- tices that are performatively enacted' (Weber 1998). As Sara 
Ahmed reveals, bodies take shape through being oriented toward other bodies, objects, and things (2006a, p. 552). Cultural exchanges then entail cross-cultural encounters as sites that encourage participants to pursue certain directions by situating themselves in relation to such things as programme recruitment materials, handbooks, and post-exchange activities, as the following sections explore. As Ahmed furthers via Butler, coming into contact with such sites and 'turning' towards such things is 'crucial to subject formation' for 'in moving this way, rather than that, and moving in this way again and again, the surfaces of bodies in turn acquire their shape. Bodies are "directed" and they take shape of this direction' (2006b, p. 16 , original emphasis).

Via this notion of direction, (dis)orientation provides an important supplement not only to performativity but also governmentality to unpick cultural exchanges' processes of subjectification. In his conceptualization of governmentality as 'the conduct of conduct' that involves the government of the self and others, Foucault advances an understanding of government from the sixteenth century where 'it designated the way in which the conduct of individuals or of groups might be directed' (1982). With the following sections exploring how programme orientations, for example, direct individuals' most personal behaviours and emotional dispositions, exchange participants' identity performances are intimately bound up with practices of governmentality. Governmentality interrogates these processes of direction by encouraging analysis of specificities, thereby enabling an exploration of the complex, diffuse operations of power that incentivise subjects to perform particular identities at different times (Foucault 1991; Rose et al. 2006; Walters 2012). Furthermore, global governmentality highlights how subjectivity and the everyday practices that constitute it are central to global power relations (Larner and Walters 2004). Global governmentality then reveals the global politics engendered by the governmentality of post-9/11 US cultural diplomacy, in particular how exchange subjects' daily lives are part of structural power relations enacted on a global terrain.

With the cross-cultural encounters of exchange carefully managed to orient participants to perform themselves in ways that secure a particular global imaginary, 'this question of direction' is therefore 'crucial to the emergence of subjectivity ... Depending on which way one turns, different worlds might even come into view' (Ahmed 2006b, p. 15). Indeed, within such encounters, counter-conducts (as the will not to be directed or governed in this way) are also enacted and identities are performed that subvert or disrupt their performative and governmental bounds. For orientation and dis- orientation always already necessitate one another; in the process of becoming orientated through exchange encounters, participants simultaneously undergo disorientation through/by the very identities and conducts these exchanges prescribe. While exchange advances and adheres to particular affective frames and colonial imaginaries to encourage the enactment of such identities and conducts, it is also vital for any analysis of exchange not to be flattened or rendered reductive through such frames and imaginaries. In their everyday lives, exchange participants' can perform themselves otherwise, structural power relations can be resisted, global orders can be enacted differently. It is by excavating the everyday of these exchanges that the ambivalence of all such crosscultural encounters and the multiplicities of identity and experience they enact can be revealed and that possibilities to disorient can be interrogated.

To encourage this ideal conduct of exchange participants, the enactment of such prescribed identities and the seeming promise such an enactment holds is intrinsically bound up with emotion. For emotions stick to bodies, leaving impressions on the surface which shape the subject and encourage particular attachments (Ahmed 2014). It is by paying attention to the affective frames of cultural exchanges that we can trace 'how subjects become invested in particular structures' (Ahmed 2014, original emphasis). With emotion serving 'as a form of ... world making' (Ahmed 2014, p. 12), exchange participants are drawn to what this world provides and willingly (or, as demonstrated earlier, unwillingly) subject themselves to the affective and relational shaping of the self that secures their place in that world. This is key to how performativity and governmentality do their work - the performance of certain identities and conducts grants rewards in the form of affiliation and community. In this manner, the cosmopolitanism embedded in cultural exchanges 'becomes a "shared object of feeling" through the orientation that is taken towards it' (Ahmed 2014, p. 13); exchange participation seemingly guarantees one's membership of a global cosmopolitan and enterprising, innovative elite. 
Emotions are therefore both governmental and performative whereby they 'depend on past histories, at the same time as they generate effects' (Ahmed 2014). What is intriguing is when such histories manifest as empire in the form of spectres and echoes of colonial power relations. Such spectres and echoes gain particular force via the performativities, governmentalities and (dis)orientations that emotion and exchange engender - within the articulation of particular national, global and neoliberal subjectivities, the particular cosmopolitan logic of tolerance by which they are shaped, the emotional attachment imbued in them, the embodied exchange encounter in which they are enacted and, of course, their internalized performance by exchange participants. The following sections trace these spectres through the everyday objects, spaces and performances of the YES programme - including pre-exchange recruitment materials, on-exchange orientations and handbooks, and post-exchange activities - that is, the governmental technologies and devices through which ideal subjectivities are accepted, regulated and enforced. While it is vital to interrogate these colonial spectres and echoes in their both subtle and crude forms, attention must also be paid to how the global imaginaries they evoke and the colonial asymmetries they perpetuate are always undergoing disorientation through their potential reorientation or rejection, i.e. performativity always entails resistance, governmentality always entails counter-conduct, orientation always entails disorientation. Of course, as the following sections reveal, resistance, counter-conduct and disorientation are not always disruptive but can be recouped to bolster the power relations of YES's cosmopolitan logic of tolerance. What is more, emotion, empire and exchange combine in cultural diplomacy to mobilize specific, complex operations of power that, via incentivising techniques, shape programme participants as governable and self-governing subjects in both enabling and constraining ways. Bringing performativity, governmentality and (dis)orientation into conversation enables one to think through and disentangle how the bounded identity categories they are required to perform both order and regulate participants' everyday lives while energizing and rewarding them. This disentangling is key to the following provocations that both illustrate and disorient the performativities and governmentalities by which this entanglement of empire, emotion and exchange operates and reveals itself. Resisting the temptation to be seduced by easy accounts of post9/11 cultural diplomacy as merely the embodiment and persistence of colonial imaginaries, this article disorients colonial logics of subjectification through the following provocations' exploration of affective exchange encounters that are always already (dis)orienting.

\section{Empire as (dis)orientating: pre-exchange investments}

The first provocation proposes that post-9/11 US cultural diplomacy and its underlying logic of cosmopolitanism suggest that empire is disorientating via its manifestation in 'unusual' sites; exchange programmes' onus on coming together, celebrating difference, and highlighting universality appear to conflict with 'where' empire 'usually' orients itself and makes itself felt. I argue, however, in the vein of critical post/decolonial scholarship, that empire is always (dis)orientating for it is in the seemingly benign/ unquestionable where empire does its work most profoundly. The cosmopolitanism embedded in these cultural exchange programmes, and the values and identities it advances as universal, coherent and accepted, are framed as a somewhat unquestionable benevolence but are in fact riven with asymmetries that have colonial echoes and make themselves felt - and felt keenly. I am not claiming to venture anything novel here; the permeation of cosmopolitanism and/with colonialism has a long history (Mamdani 1996, Cheah and Robbins 1998, Fanon 2001, Bell 2002, van der Veer 2002, Gilroy 2005, Lisle 2006, Jabri 2007, Mignolo 2010, Bhambra 2011, Go 2013, Opondo 2016). Rather, I am drawing attention to how that history is disoriented to provoke alternative orientations through key affective investments around the virtuous, the desirable and, subsequently, the desired. As the preceding section revealed, exchanges are highly affective encounters where cosmopolitanism becomes a 'shared object of feeling' around which exchange subjects are oriented in powerful ways and in which these subjects become acutely invested (Ahmed 2014). With YES, these investments are especially generated before the exchange through particular governmental technologies: programme recruitment materials. This section takes YES Abroad call for applications (CfAs) in programme digital spaces as the technologies under analysis to reveal how the virtuous, the desirable and the desired operate to order participants' ideal YES conduct through their written and visual devices.

The virtuous manifests in how participation in these cultural exchange programmes is oriented as seemingly securing one's identity as a global cosmopolitan citizen who embodies and espouses seemingly universal and unproblematic values and is therefore advanced as an incontestable and even commendable means 
of fostering a global cosmopolitan society. In the case of YES and its cosmopolitan logic of tolerance, participation is positioned as the means to secure a more tolerant, open, and globally competent citizenry:

\author{
Students on YES Abroad learn about the world first-hand, whether it's another language, current \\ events, or how to translate information into the global context. Say YES to YES Abroad! \\ Apply by December 3, 2019 at yes-abroad.org/how-to-apply to begin your journey. \#YESAbroad \\ \#ApplyNow \\ - YES Abroad @KLYES, 23/11/2019 (Yes Abroad 2019c)
}

By being oriented and shaped in this way, exchange participants can then effect the desirable wherein such identity performances can enable a more tolerant world. Indeed, if orientations are, as Ahmed (2006b, p. 8) claims, 'how we begin' where 'The starting point for orientation is the point from which the world unfolds', exchange participants orient themselves towards this cosmopolitanism and the particular subject formation this exacts due to the promise of this cosmopolitanism to make more desirable (here tolerant, inclusive, accepting) worlds. CfAs imperatively urge prospective YES Abroaders to:

Join the global community of YES Abroad today by submitting your application yes-

abroad.org/how-to-apply.

- YES Abroad @KLYES, 10/12/2019 (YES Abroad 2019g)

\author{
Image Caption: LEARN WITH THE WORLD \\ Breaking bread took on a whole new meaning when Bryca shared a traditional Orthodox Christmas \\ breakfast with her host family in Bosnia and Herzegovina. What sorts of new foods will you try \\ abroad? Apply to YES Abroad at yes-abroad. org/how-to-apply by Dec 3. \\ \#YESAbroad \#ApplyNow \\ - YES Abroad @KLYES, 12/11/2019 (YES Abroad 2019b) \\ Image Caption: CONNECT WITH THE WORLD \\ While school in your host country will be different than what it's like at home, \\ on YES Abroad you'll see that friendship is universal. The world is out there - take the first step. \\ [...] \#YESAbroad \#ApplyNow \\ - YES Abroad @KLYES, 2/11/2019 (YES Abroad 2019a)
}

To be directed and to direct oneself in this way then also necessitates the desired. In their reiteration of the norms of YES's logic of tolerance which take them in certain directions, YES subjects therefore orientate themselves 'toward some objects more than others', including 'objects of thought, feeling, and judgment, and objects in the sense of aims, aspirations, and objectives' (Ahmed 2006a, p. 553). For cosmopolitanism here is also 'a rationality of government', whereby rationalized strategies and techniques are devised and operationalized to direct exchange participants by acting on their desires and aspirations. Indeed, the conduct of conduct involves a range of heterogeneous authorities, including technologies of government 'traversed and transected by aspirations', whose aim is to mould actions and conducts of the governed in desired directions to produce 'certain desired effects' and avert 'certain undesired events' (Rose 2007, $p$. 52). Governmentality therefore does its work through these recruitment technologies by forging a symmetry between that desired by exchange participants and their desired conduct by governmental forces.

Image Caption: Build a Global Future. Say YES to YES Abroad

Students on YES Abroad are cultural ambassadors. Take the first step and build a global future with YES Abroad. [...]

\#YESAbroad \#ApplyNow

- YES Abroad @KLYES, 26/11/2019 (YES Abroad 2019d)

Why not apply to YES Abroad? It's an incredible, free, once-in-a-lifetime opportunity that is available to anyone. The world is out there. Take the first step! Complete your application at yesabroad.org/how-to-apply! The deadline is tonight at 11:59pm ET. \#YESAbroad \#ApplyNow - YES Abroad @KLYES, 03/12/2019 (YES Abroad 2019f) 
On \#YESAbroad you will learn important life skills including communication, independence, maturity, confidence, becoming more open-minded and learning about yourself! Take education outside the classroom and say YES to YES Abroad! \#ApplyNow at yes-abroad.org/how-to-apply by Dec.

- YES Abroad @KLYES, 01/12/2019 (YES Abroad 2019e)

As all of these CfAs demonstrate, the attachment to cosmopolitanism that YES encourages depends for its operation upon an interlinked investment in the virtuous, desirable and desired produced by the obfuscation of cosmopolitanism and colonialism's entangled history. Echoing and complicating study abroad and voluntourism advertisements (which have long come in for critique for exhibiting, for example, white saviour complex), CfAs as governmental technologies therefore exemplify both this fallacy of empire's emergence in 'unusual' sites and this tension of empire as always already (dis)orientating in several ways. First, by urging YES Abroad students that 'The World is Out There. Take the First Step' and 'Make the World Your Classroom' (YES Abroad 2018b, 2018a) with US smiling students sitting in the midst of Others, YES Abroad recruitment materials endorse 'the notion that the entire world is preordained as the property of the American student', encouraging the performance of YES Abroaders' development of cosmopolitan sensibilities to be oriented by colonial spectres of entitlement and narcissism (Zemach-Bersin 2009, p. 307). YES Abroad host countries and the Others who inhabit them are reductively represented as a passive 'world' 'waiting' both for the YES Abroad student's 'discovery' and to fulfil these US students' needs and desires. Such rhetoric, Zemach-Bersin argues, 'inadvertently evokes the sexual and gendered language of colonialism' (Zemach-Bersin 2009, p. 307). Here colonial depictions of foreign lands via passivity and submissiveness combine with the spectres of entitlement and narcissism to position US students as 'not just more important, but far more active, real, and powerful than the world beyond the borders of the US' (Zemach-Bersin 2009, p. 307).

Second, the promise to 'learn with' and 'connect with' is consequently unsettled; for these recruitment materials' pluralist aims of all exchange participants simultaneously bridging differences come at the cost of commodification and exoticisation of the bodies of certain participants (Muslim others). bell hooks reminds us that 'The commodification of Otherness has been so successful because it is offered as a new delight, more intense, more satisfying than normal ways of doing and feeling' (1992, p. 366). CfAs' declarations of providing once-in-a-lifetime opportunities to 'know' and 'understand' these cultures through these affective encounters reflects and embodies what hooks terms 'eating the Other', where YES promotes a commodity culture within which Otherness 'becomes spice, seasoning that can liven up the dull dish' that is (predominantly white) US culture (hooks 1992, p. 366). Sometimes this manifests literally where 'Learn with the World' reduces potentially rich cross-cultural encounters and experiences down to 'What sorts of new foods will you try abroad?' (YES Abroad 2019b); other times this manifests through 'learning about the world first-hand' rendering the Other useful for garnering cultural, political and economic capital that signals YES Abroad students' cosmopolitan tolerance - whether through acquisition of languages, topical events or the ability to 'translate information into the global context' (YES Abroad 2019c). Such advertising exemplifies, how 'the commodification of difference promotes paradigms of consumption wherein whatever difference the Other inhabits is eradicated, via exchange, by a consumer cannibalism that not only displaces the Other but denies the significance of that Other's history through a process of decontextualization' (hooks 1992, p. 373). To further hooks, these CfAs 'enable the voice of the Other to be heard by a larger audience even as it denies the specificity of that voice, or as it recoups it for its own use' (hooks 1992, p. 373).

Third, what such performativities reveal is that the accumulation of such skills though encounters with the Other orients the embodiment of cosmopolitan tolerance around the self-development of the American student in ways that align with colonial capitalist dynamics. Emphasizing 'your journey', (YES Abroad 2019c) 'learning about yourself' (YES Abroad 2019e) and 'building your community', ${ }^{1}$ CfAs repeatedly inform YES Abroad students that such encounters are geared towards self-enhancement to exhibit the prized neoliberal skill set required to operate in a global world. Here investment takes on a multi-layered significance through the entanglement of the affective and financial, the individual and the collective. For 'building a global future' through programme participation enables participants to demonstrate they possess the competencies and dispositions required for their 'successful' futures in the neoliberal economy as enterprising individuals, contributing national citizens, and open global citizens. As Wanda Vrasti (2013) reminds us, such entrepreneurial conduct and skills development are therefore not solely narcissistic, but 
bound to emotional competencies and citizenship responsibilities oriented around investment in the future of multiple communities. YES encourages participants here to orient themselves vis-a-vis dual constructs of the self that are colonial in origin. ${ }^{2}$ Post-9/11 US cultural exchanges therefore 'orient' in a dual sense through the disorienting subjectivities produced by the entanglement of empire, emotion and exchange.

\section{Empire (dis)orients: on-exchange alignments}

The second provocation is that the entanglement of emotion, empire and exchange can (dis)orient or offcentre subjects. This is not to suggest that subjects are ever 'centred' in the sense of being fixed, stable, immutable. As the article earlier explored, subjects are always in the process of becoming, as the meanings surrounding identities are ever-changing and undecidable. But cultural diplomacy's repetitious performative acts naturalize the familiar national, global cosmopolitan and enterprising neoliberal identities that exchange participants are required to enact and regulate them within the norms of its underlying cosmopolitanism. With exchange subjects affectively invested in cultural diplomacy's cosmopolitan structures, they are encouraged to perform identities that are always already (dis)orienting, that orient and disorient. For in the emergence of subjectivity, orientation and disorientation work together to produce lines that direct, and in post-9/11 US cultural exchange bringing subjects into regulation and alignment therefore becomes intensified due to the multiple subjectivities participants must embody. This provocation therefore builds on the previous provocation's focus on orientation as investment to centre on orientation as alignment - as lines that direct, that mark out the perimeters of behaviours that exemplify the ideal YES subject, that exchange participants (ought to) follow when oscillating between prescribed national, global and neoliberal identities. Ahmed urges us to pay attention to alignment for 'the social pressure to follow a certain course, to live a certain kind of life, and even to reproduce that life, can feel like a physical press on the surface of the body, which creates its own impressions for sure. We are pressed into lines' (2006a, p. 555). In YES, such points of pressure and alignment are numerous in terms of the on-programme requirements demanded of YES participants, but the governmental technologies that are particularly illuminating for this provocation are orientation sessions and programme handbooks.

Orientation sessions abound in YES, with students required to attend pre-departure, post-arrival, mid-year and end-of-stay/re-entry orientations. Post-9/ 11 US cultural exchange involves orientations around different lines and directions to produce prescribed familiar national and cosmopolitan global identities, with exchange participants then having to orientate around a neoliberal subjectivity to keep these in line. But this performative relation is inherently disorientating; there is always the possibility for it to fracture open due to the contingency and undecidability of all performatives. YES orientation sessions, their sheer volume throughout the exchange year and their various objectives therefore strive to keep exchange participants in line, to keep their bodies orientated towards the ideal identities they should constitute. Orientations and accompanying handbooks therefore rigorously define the limits of participants' ideal YES conduct (lines not to be crossed) while seemingly energizing participants to enact their YES experience autonomously (as responsibilised, governable and self-governing subjects they choose the lines and paths they follow). Every aspect of everyday exchange life is brought under regulation to be governed by both students themselves and hosts. For example, Cultural Information Sheets provide hosts country-specific information in infographic form under the headings of school, family life, personal interactions, food and culture, and personal hygiene, that impart, for example, that 'Senegalese teenagers generally take a quick (5 minute) shower twice a day and as Muslims wash before praying' (YFU n.d.b). Student orientations have sessions aligned under the selfsame headings, while the YES Student Handbook dedicates a section urging students to 'Understand Your Own Country First' (American Councils 2016). Here, with 'personal hygiene' in particular being reiteratively ordered through resources for both students and hosts, we see how they mirror 'forms of identification, registration, and discipline' which 'emerged in tension and in tandem with technologies of self-control that fostered notions of cleanliness, domesticity, ethnicity, and civilization' (Pels 1997, 165). Orientation sessions and handbooks therefore parallel colonial apparatuses of observation and (self-)control based on anthropological knowledge to 'know' the Other/self as Other and to regulate and govern accordingly. These technologies can then outline the boundaries of appropriate/inappropriate conduct and provide direction through 'support advice' on how best to perform the ideal YES subject. 
Students must work on the self by following this direction. The YES Student Handbook is permeated with a series of imperatives that order their intimate lives through a series of emotional behavioural norms that seek to secure this ideal tolerant self: they must 'show appreciation' (American Councils 2016, p. 39), 'look for the positive' (American Councils 2016, p. 40), while in terms of 'tolerance' they must accept differences 'as part of the American experience' and 'strive to be open-minded' (American Councils 2016, p. 66). Under General Tips for a 'successful' exchange, the handbook ends with reiterative imperatives that they must be 'respectful', 'honest', 'open-minded' and 'positive' (American Councils 2016, p. 66). YES students are encouraged to enact these behaviours to perform themselves as the affable Other - as the reductive familiar national citizen, the willing-to-share cosmopolitan global citizen, and the flexible, adaptable neoliberal citizen. Ahmed spurs us to think of this alignment 'in terms of assimilation, as a politics of following the straight line even as a deviant body' (2006a, p. 567). For while they identify 'precisely with what repudiates [them]' (2006a, p. 568), the identities they perform must not be too different, never in the realm of the abject. Ultimately, YES students must orient the self around the ideal embodiment of tolerable difference. YES students, their Othered bodies and conducts, by moving in these host spaces leave their impressions on US bodies but should only do so in ways that enhance US hosts cosmopolitan tolerance without inconveniencing them too greatly.

They thereby enact the 'good Muslim', a dehistoricised political identity effected through 'culture talk' (Mamdani 2002). Indeed, the Student Handbook devotes a section to 'Understanding Yourself as a Product of Your Own Culture' followed by a section on 'Adjustment' (American Councils 2016). This also extends to how 'American culture' is then posited alongside, with volunteerism promoted as a key US value and as a programme requirement through a community service enhancement theme. At orientations these requirements are reiteratively enforced whereby YES students eagerly perform volunteer acts on-exchange because of the rewards they offer: first, the 'enhancement' of the self as entrepreneur through the procurement of the skill set required to achieve economic success/career advancement; and second, the outward marking of the self as public-spirited altruist (or, indeed, grateful visitor). Far from simple acts of kindness, these activities imbue students with social and economic capital. Wanda Vrasti draws attention to how volunteerism 'becomes a standard reference for what it means to be good' (2013, p. 4); indeed, it has 'come to occupy a (suspiciously) firm moral grounding that demands applause' and as such, should both trouble us and command its interrogation (2013, original emphasis). There is a self-gratification in providing a service to one's fellow citizens that is only made possible by an asymmetrical demarcation between helper/helped. Only particular selves, those of a certain socioeconomic class, can engage in such acts and merely be incentivised 'for such participation through awards, contests, and acknowledgments in newsletters and on websites' (US State Department 2010, p. 12).

Dual techniques of visibility and competition underpin such incentives; students' performances of the good volunteer and good Muslim must be seen by others through their public display. PIE's monthly newsletter, The FLEX-YES EXPRESS, included a repeat feature entitled 'Community Service: The Race is On!', an alphabetical list of PIE YES students and their completed hours of community service. Via this surveilling technology, students monitor their conduct but also measure themselves against their fellow YES students, competing for the ultimate accolade of being a 'Star Volunteer' or receiving a 'Community Service Award' for exceeding community service requirements. The dual techniques of visibility and competition render a greater number of completed hours a mark of how benevolent, proactive, assiduous, and engaged (and therefore how good a global and national citizen) these students are, but also a mark of how enterprising, motivated, goal-oriented and successful (and how good a neoliberal subject) they are. These logics seek to cement an entrepreneurial self whose internalization of the 'American' norm of volunteerism facilitates its vacillation between national and global identities.

Such culture talk extends to how host families must also enact themselves as the ideal subject, notably through their direction of students to align themselves with appropriate YES behaviours and to facilitate such adjustment. Host handbooks such as the Cultural Handbook for the YES Program simultaneously encourage a complex understanding of culture that avoids misconceptions and stereotypes that are 'extremely ethnocentric and one-dimensional' (AFS-USA YES Team 2010, p. 28), while providing 'advice' that bolsters the ethnocentrism they seek to transcend. Country-specific handbooks each contain a generic section on culture that is inspired by the work of Geert Hofstede widely-critiqued for its essentialisations, 
while also distinguishing cultural generalizations (good) from cultural stereotypes (bad) as the basis for cross-cultural understanding in YES exchange encounters. Country-specific handbooks go so far as to say: 'To help you along in this process of mutual discovery that the hosting experience presents, it is often useful to look to cultural generalizations' (AFS-USA YES Team 2010, p. 16). Host resources in fact hinge upon 'the assumption "that every culture has a tangible essence that defines it and then explains politics as a consequence of that essence"' (Mamdani 2004, p. 17 cited in Brown 2006, p. 20). Colonial spectres of classification that mobilize cultural exoticisations and essentialisations are immediately apparent within the 'Common Cultural Traits in YES Program Countries' which hosts should use 'as a guide to understand the cultural context for your student's behaviour' (YFU n.d.a, p. 1). While the caveat is provided that 'not all traits apply to all YES students', (YFU n.d.a, p. 1)' these lengthy tables document a taxonomy of behaviours (through headings such as 'Food and Meals' and 'Social Interactions'), simultaneously producing a detailed Otherness and succinctly reducing YES students' differences into a sweeping, generic Other that can be easily managed by the particular tolerance exhibited through host family direction and guidance provided (through an imperative corrective in bold). For example, in terms of facilitating YES students' adoption of emotional behavioural norms the following appears:

In some YES cultures, the student...

Doesn't openly express

feelings or shows only positive emotions.
Because at home...

Expressing negative emotions is avoided. Body language, rather than direct verbal communication, might be used to convey emotions. $\sqrt{ }$ Encourage students to share feelings and ask probing questions to gage their emotions. (YFU n.d.a, p. 4).

While students must be 'open-minded', hosts are given helpful tips to align and 'correct' behaviours in order to generate more palatable, affective encounters in the US. Hosts are not reciprocally open-minded or respectful of 'culture' but rather must encourage students to drop such behaviours and conform to a US superior ideal. Handbooks and orientations explicit purpose is for hosts 'to learn about your YES student's cultural background and support their adjustment in the US' (YFU n.d.c).

YES can then claim to account for difference while handbooks instil ethnocentric and myopic perspectives that shape families' encounters with the Others they host. Country-specific handbooks are interspersed with testimonies from US host families to help guide future hosts' encounters with YES students. In the Handbook for Host Families for Pakistani Participants, under the heading 'Halal foods', features one host family: 'We had fun finding multiple ways of cooking chicken and other non-meat dishes. Families need to be willing to have fun with this: it isn't going to go away' (17). Cultural difference cannot be eradicated so therefore must be embraced in a palatable manner. In the Cultural Handbook for Afghanistan, 'advice' for host families regarding awareness and respect of students' diversity continually entrenches crude Orientalizing cultural stereotypes. Hosts are enlightened that Afghanistan is 'an economically backward country' (American Councils 2004, p. 8). but also made aware that, 'Despite the generally low standard of living, there are relatively prosperous Afghan families ... Do not automatically assume that your YES student from Afghanistan is poor!' (American Councils 2004, p. 9) as 'Although among the poorest countries in the world, some Afghans are very wealthy - even by American standards' (American Councils 2004, p. 16). Hosts are accordingly advised that 'Showing a student who has possibly spent most of his childhood growing up with Bugs Bunny cartoons how to turn on the TV could be offensive or give the wrong impression' (American Councils 2004, p. 15). As ideal YES subjects, both students and hosts are pressed into lines that are aggressively disorienting. Hosts must manage difference simultaneously through its essentialisation and the embodiment of particular cosmopolitan values (as the hospitable host, loving family, tolerant American), while students, whether via assimilation or self-Orientalism, must embody cultural differences that are neutral, safe, 'tolerable'. 


\section{Empire disoriented: post-exchange incentives}

But as this article earlier affirmed, while essential to call attention to these colonial logics of subjectification, this should not then lead to a flattening or reification of affective exchange encounters that are always already (dis)orienting. This section seeks to account for the complex, heterogeneous and, at times, subversive processes of identity formation that are enacted in these exchange encounters. This third provocation therefore posits that tracing colonial echoes and spectres in these exchanges reveals empire as disoriented, as that which is analytically 'less conventional'. While an arguably 'conventional' analysis oriented around a neo-colonial logic and an imperialistic 'America' would be seductive in its simplicity, it is also problematic because it obscures the governmental and performative complexities at work within these cultural exchange programmes. A conventional articulation where top-down power is at play would be myopic. An examination of YES's everyday practices reveals this is not merely a neo-colonial logic, as Kabir (2011) contends; something more complex is at operation. While colonial echoes and spectres are central to these cultural exchanges, it is crucial that any analysis consider how exchange practices are simultaneously constraining and enabling, disciplining and incentivising. A top-down power formation is not operating within these post-9/11 US cultural diplomacy programmes; rather, as YES reveals, these exchanges operate through modes of governmentality that produce enabled, energized subjects in ways that mask the operations of power within that production and make those subjects more easily governed (Mills forthcoming).

This provocation builds on the claims of the previous two around orientation as investment and alignment. It pursues how investment and alignment work together to reveal empire as disoriented, and how the entanglement of empire, emotion and exchange through governmentality incentivises exchange subjects' ideal identity performances after the exchange through potential reward. Following lines involves social investment for 'Such investments promise return (if we follow this line, then this or that will follow)' (Ahmed 2006a, p. 555). Indeed, it is the promise of arrival at the ideal YES subjectivity (as youth ambassadors of one's nation, as tolerant cosmopolitan citizens, and as globally competent possessors of a neoliberal skill set) and what this then offers in return - further grants (e.g. YES Alumni Grants Competition), training opportunities (e.g. YES Alumni Training of Trainers Workshop), university places/ scholarships (e.g. Saginaw Valley State University YES Alumni Scholarship), career prospects - when these lines have been followed 'correctly', that encourages their 'appropriate' adherence.

But such rewards do not just end with the individual. The affective investments of YES are also always aligned with the enactment of an ethical responsibility to the communities (YES programme, home country, global society) that programme participation exacts. A (dis)orientation logic therefore enables us to trace how the afterlives of exchange programmes are directed by and bound to a range of ethopolitical incentives. Ahmed argues that 'For a life to count as a good life, it must return the debt of its life by taking on the direction promised as a social good, which means imagining one's futurity in terms of reaching certain points along a life course' (Ahmed 2006a, p. 554). In YES, this debt becomes particularly potent through the crafting of the future self through post-exchange activities, most notably the Two-Year Home-Country Physical Presence Requirement. A proviso of YES students' visa, this requirement also stipulates that YES students should return home galvanised with 'American' values and skills to improve their national settings and impart all they have learned about US culture as youth ambassadors. Host families are particularly tasked with ensuring that this requirement is enforced. While YES seeks to empower students to take the initiative to secure their academic, professional and economic success, they must only do so through strict adherence to rules. YES orients students' development along lines pursued not (solely) out of self-interest but also national interest. YES alumni therefore must imagine their futurity as achieving personal and national success.

But the ambivalence of all cross-cultural encounters is such that these orientations are perhaps not easily nor willingly realized. Lines are crossed or not followed through the rejection of these prescribed identities, counter-conducts or failed orientations (when bodies cannot be brought into alignment). The Home-Country Physical Presence Requirement proves interesting once more for in the case of Afghanistan, returning students were in fact tasked with 'rebuilding' the country. The overt contradictions underlying this regulatory system were not lost on Afghan YES students and their families back home. Since 2005, the second year

$11 \mid 17$ 
of Afghanistan's YES involvement, students asylum-seeking in Canada rose increasingly until the programme's suspension in 2011. These contradictions produce affective fissure lines that cannot be bridged, with teenagers and their parents tearfully urging these conducts. These conducts are marked as abject identity performances of the ideal YES subject by both officials in Kabul and DC, while for others these conducts are demarcated by a much more overt colonial repudiation as the 'ungrateful Other' or 'bad Muslim' (see Woods 2011). But are these YES students merely enacting the neoliberal subjectivity they have been encouraged to perform - ingenious, resourceful, opportunistic? If such fissure lines arise as part of following these ideal lines of orientation, should YES subjects as enterprising selves not pursue other lines when the potential rewards for the self-optimised future self are that much greater? Or if these fissure lines become so great that their very YES participation marks them as a Fanonian 'been-to' so that a return home threatens their very life (McMahon 2009), are such conducts - far from resistance or a counterconduct - incentivised merely by the desire not to thrive but simply survive? Here in this undecidability, (dis)orientation is at its most unruly and compelling through the entanglement of empire, emotion and exchange. This provocation therefore refuses an easy colonial/colonised logic, illustrating, rather, the disorientation effected by the ambivalence of affective exchange encounters, where investment and alignment as governmental regimes both enable and constrain, and counter-conducts can hold subversive potential.

\section{Disorient empire, reorient cultural diplomacy: beyond exchange reimaginings}

The final provocation then asserts that empire must undergo disorientation, whereby the logic of disorientation enables empire to be challenged and disrupted. Ahmed argues that 'Moments of disorientation are vital' for they 'throw the world up' (2006b, p. 157) and give 'what is given [a] new angle' (2006b, p. 162). This necessity to disorient empire, to unsettle its seeming 'givens', to open up another angle on the world it generates, may seem evident due to the violent Othering practices, erasures and disavowals enacted by the colonial echoes and spectres in these post-9/11 US cultural exchange programmes. But by analysing these programmes in their messy complexity and the particular worldmaking that post-9/11 US cultural diplomacy effects, this article's exploration of disorientation can also open up alternative, creative spaces where post-9/11 US cultural diplomacy and the self-Other relations comprising it could be reimagined, leading to subversive reorientations. As Martin \& Rosello affirm, 'When the connection between orientation, disorientation and the existence of a hegemonic map is disturbed and interrupted, then a moment of radical disorientation occurs' $(2016$, p. 3).

Disorientation therefore holds within it radical possibility. Indeed, for Ahmed, the point of disorientation is 'to make the "familiar" strange, or even to allow what has been overlooked, which has been treated as furniture, to dance with renewed life' (2006a, p. 569). By making strange what performative and governmental regimes have established as the 'familiar', the 'taken-for-granted', the 'natural' of these exchange programmes, other daily exchange lives can be experienced, other identities can be performed, other worlds can be enacted by/in cultural diplomacy. In this regard, Ahmed illustrates how disorientation enables a queer politics, for 'To make things queer is certainly to disturb the order of things' (2006b, $p$. 161). A queer politics therefore unsettles how post-9/11 US cultural diplomacy has been directed, ordered and managed, 'thereby creating other kinds of connections were unexpected things can happen' (2006b, p. 169) and opening up the possibility 'to form new patterns and new ways of making sense' (2006b, $p$. 171). This article therefore opens up a space to grapple with cultural diplomacy's entanglement of emotion, empire and exchange to interrogate how cultural exchanges could enact more ethical encounters and enable alternative subjectivities and imaginaries. In short, cultural diplomacy can, should and must be done differently. This article's analytical disorientation can therefore open up the opportunity for a reorientation of cultural diplomacy.

A note of caution is necessary here: it is vital that disorientation and reorientation do not come to signify as ideals which we then come to orient ourselves around as a seductive 'new orientation' (Martin and Rosello 2016 , p. 9). The dangers of this would collapse any potential for radical possibility and, conversely, potentially, reenact the colonial spectres under critique for 'idealising disorientation also means exoticising' (Martin and Rosello 2016, p. 7). More critically, as this article has demonstrated, disorientation is always already experienced in post-9/11 US cultural diplomacy. It is in moments of disorientation that orientation 
is realized; therefore, disorientation is not always radical. Bodies can be reoriented in ways that bolster rather than disturb that orientation to the world or, as demonstrated previously, resistance, counter-conduct and disorientation are recouped to sustain particular worlds.

The point, rather, 'is what we do with such moments of disorientation, as well as what such moments can do - whether they can offer us the hope of new directions, and whether new directions are reason enough for hope' (Ahmed 2006b, p.158). Again, this is not to slip into idealization; as Daggett argues, this is 'not a dreamy, blinkered hope, blind to dangerous possibilities, but rather a strategic hope borne of an appreciation for the tenuousness of (re)orientations, which are especially vulnerable in moments of disorientation' (2015, p. 363). For 'If orientations point us to the future, to what we are moving toward, then they also keep open the possibility of changing directions, of finding other paths ... where we can find hope in what goes astray' (Ahmed 2006a, pp. 569-70). This possibility also gives hope that in cultural exchanges, participants can find other ways to perform themselves, to produce lines that do not reproduce the prescribed orientations of post-9/11 US cultural diplomacy 'but instead create new textures on the ground' (Ahmed 2006a, p. 570). It is also to find hope in failure - when identities do not cohere to their prescribed bounds, when lines that regulate and govern are crossed - and the productive openings and possibilities these forms of 'doing cultural diplomacy otherwise' can then enable for cultural exchange and encounter. So when YES students perform their exchange lives differently, they are not punished but embraced. As Ahmed affirms, 'If we see failure to sink into the chairs of convention as a political gift, then other things might happen' (2006b, p. 177). Indeed, if YES subjects 'became savvy' (Brown 2006) about tolerance and its violent practices of subjectification, they could, from this politically engaged position, performatively enact themselves differently. YES exchanges could become disorienting sites enabling candid, complex articulations of inequality, abjection and violence that tolerance as a mode of governmentality seeks to suppress. This provocation therefore situates and embraces disorientation as an effect of how we do politics through the conduct of our daily lives that can lead to hopeful reimaginations of post-9/11 US cultural diplomacy encounters.

\section{Upsetting the furniture: the possibilities of disorientation}

Engagement in such work also entails disorientation as a scholar. For my everyday engagement in this work enacts a particular politics - in my (need for greater) reflexivity as a scholar of privilege, the ethical choices to pursue 'non-traditional' sites of enquiry or the power relations enacted by my own (digital) ethnographic encounters with cultural diplomacy. Above all, it forces one to think in disorienting ways about this work and about the possibility this can open up. To play on Ahmed's claim in the previous section, this enables one to think about the failure to sink into the chairs of scholarly convention as a political gift and the alternative imaginings this enables. This conclusion therefore also wishes to reflect on how upsetting one's academic furniture is vital to ensure this research does not result in the reductive flattenings and violent reifications that it seeks to trouble and disrupt. It is important as scholars that we do not become so oriented, so fixed, so settled, so comfortable that our engagements with empire fail to account for the ambivalence, complexity and messiness that lies at the heart of everyday exchange encounter. In its disentanglements of empire, emotion and exchange, this article therefore seeks to trace the (dis)orienting encounters of post-9/11 US cultural diplomacy and to then itself serve as a disorienting encounter with post9/11 cultural diplomacy.

First and foremost, this article has sought to critically explore the (dis)orienting encounters of cultural diplomacy through four critical moves that traverse the YES programme. First, post-9/11 US cultural diplomacy and its logic of cosmopolitanism suggest empire is disorientating via its manifestation in 'unusual' sites; exchange programmes' onus on celebrating difference and highlighting universality appears to conflict with 'where' empire 'normally' orients itself and makes itself felt. But analysing the affective investments imbued in YES recruitment materials reveals how empire is always (dis)orientating for it is in the seemingly benign/unquestionable where empire does its work most profoundly. Second, the entanglement of emotion, empire and exchange can (dis)orient subjects through the ever-shifting, often conflicting 'ideal' subjects (familiar national/cosmopolitan global/enterprising neoliberal) that exchange participants are impelled to perform through technologies of alignment such as YES orientation sessions and programme handbooks. Third, tracing colonial echoes and spectres in these exchanges reveals empire 
as disoriented, as that which is analytically 'less conventional'. An arguably 'conventional' analysis oriented around an imperialistic 'America' would be seductive in its simplicity but is problematic, obscuring the governmental and performative complexities at work and tensions and contradictions which arise within these programmes' afterlives. Finally, disorientation enables empire to be challenged and disrupted, opening up creative possibilities to reimagine post-9/11 US cultural diplomacy and the self-Other relations comprising it. This paper's analytical disorientation could then lead to a reorientation of cultural diplomacy.

By engaging with cultural diplomacy in this manner, this article aims to resist reductive neo-colonial insights and 'think with' performativity, governmentality and disorientation to enable inventive provocations that retain an openness and complexity to cultural exchanges' messy actualities. This article thereby seeks to be a disorienting encounter with post-9/11 cultural diplomacy itself. By disentangling this nexus of empire, emotion and exchange in this way and by urging us to upset the disciplinary furniture that likewise orders what is deemed 'familiar', 'natural' and 'normal', we can open up the possibility to forge new lines, new directions, new (dis)orientations that have hope for the future. Of course, 'What inspires both anxiety and hope is that it is not yet obvious whether, and how, reorientation will be achieved' (Daggett 2015, p. 375). But as Sam Okoth Opondo affirms, 'To think and enact a diplomacy that reveals and seeks to delink itself from the logics of colonial difference ... is not a utopia' (2016, p. 51). This anxious hope/hopeful anxiety is therefore vital to ensure we do not sink back into our comfortable armchairs of scholarly convention but remain open to the politics of radical possibility for cultural diplomacy.

\section{Notes}

1. See for example the additional CfA where Others are rendered as teaching tools for US students edification: In Ghana, Avery built relationships with local sellers at the market and was able to learn first-hand about the agriculture supply chain. What will you learn - and from whom? \#ApplyNow to YES Abroad and start building your community today. yes-abroad.org/how-to-apply. \#YESAbroad. - YES Abroad @KLYES, 5/11/2019. Available at: https://twitter.com/klyesabroad/status/ 1191747088385814528?s=21.

2. I thank Miloš Jovanovic for helping me to strengthen this connection.

\section{Acknowledgments}

This article draws upon and develops arguments from my forthcoming book with Routledge New International Relations Series, Post-9/11 US Cultural Diplomacy: The Impossibility of Cosmopolitanism. I am grateful to fellow participants in the 'Empire Off-Center' workshop in Göttingen, particularly Banu Subramaniam and Priya Gopal for thought-provoking questions and conversations on this paper and the wider project. Warm thanks go to Giulia Carabelli and Miloš Jovanović for my invitation to this workshop and for their guidance and support as editors of this special issue. Thanks also to the anonymous reviewers for their constructive comments.

\section{Disclosure statement}

No potential conflict of interest was reported by the author.

\section{Note on contributor}

Laura Mills is a lecturer in International Relations at the University of St Andrews. Her research critically explores how everyday life and culture are co-constitutive of global politics through examinations of cultural diplomacy, war, militarism, security and aesthetics. Her first monograph - Post-9/11 US Cultural Diplomacy: The Impossibility of Cosmopolitanism - is forthcoming with Routledge New International Relations Series. She is the founding co-editor of Openings, a creative interventions section in the journal Con- temporary Voices: The St Andrews Journal of International Relations.

\section{ORCID}


Laura Mills http://orcid.org/0000-0001-8137-5303

\section{References}

AFS-USA YES Team. 2010. Cultural handbook for the YES program.

Ahmed, S., 2006a. Orientations: towards a queer phenomenology. GLQ: A Journal of Lesbian and Gay studies, 12 (4), 543-574.

Ahmed, S., 2006b. Queer phenomenology: orientations, objects, others. Durham: Duke University Press.

Ahmed, S., 2014. The cultural politics of emotion. Edinburgh: Edinburgh University Press.

American Councils, 2004. Cultural handbook for Afghanistan. Washington, DC: American Councils.

American Councils, 2016. YES student handbook. Washington, DC: American Councils.

Barad, K., 2007. Meeting the universe halfway: quantum physics and the entanglement of matter and meaning. Durham: Duke University Press.

Bell, V., 2002. The violence and the appeal of raciologies: colonialism, camps and cosmopolitan utopias. Theory, culture \& society, 19 (4), 245-254.

Bhambra, G., 2011. Historical sociology, modernity, and postcolonial critique. American Historical Review, 116 (3), 653-662.

Brown, W., 2006. Regulating aversion: tolerance in the age of identity and empire. Princeton: Princeton University Press.

Butler, J., 1988. Performative acts and gender constitution: an essay in phenomenology and feminist theory. Theatre Journal, 40 (4), 519-531.

Butler, J., 1990. Gender trouble: feminism and the subversion of identity. London: Routledge.

Cheah, P., and Robbins, B., 1998. Cosmopolitics: thinking and feeling beyond the nation. Minneapolis: University of Minnesota Press.

Daggett, C., 2015. Drone disorientations. International Feminist Journal of politics, 17 (3), 361-379.

Dolphijn, R., and van der Tuin, I., 2012. "Matter feels, converses, suffers, desires, yearns and remembers." Interview with Karen Barad. In: R. Dolphijn and I. van der Tuin, eds. New materialism: interviews \& cartographies. Michigan: Open Humanities Press, 48- 70.

Fanon, F., 2001. The wretched of the earth. London: Penguin Books Ltd.

Foucault, M. 1982. The subject and power. Critical inquiry, 8 (4), 777-795.

Foucault, M., 1991. Governmentality. In: G. Burchell, C. Gordon, and P. Miller, ed. The Foucault effect: studies in governmentality. Hemel Hempstead: Harvester Wheatsheaf, 87-104.

Foucault, M., 2008. The birth of biopolitics: lectures at the collège de France 1978-1979. Basingstoke: Palgrave Macmillan.

Gilroy, P., 2005. Postcolonial melancholia. New York: Columbia University Press.

Go, J., 2013. Fanon's postcolonial cosmopolitanism. European Journal of Social Theory, 16 (2), $208-225$.

hooks, b. 1992. Eating the other: Desire and resistance. In: Black Looks: Race and Representation. Boston: South End Press, 21-39.

Jabri, V., 2007. Solidarity and spheres of culture: the cosmopolitan and postcolonial. Review of international studies, 33 (4), 715-728.

Kabir, A.H., 2011. A new discourse of 'international understanding': nothing but 'americanism'. Critical Literacy, 5 (1), 38-50.

Larner, W., and Walters, W., eds., 2004. Global governmentality: new perspectives on international Rule. London: Routledge.

Lisle, D., 2006. The global politics of contemporary travel writing. Cambridge: Cambridge University Press.

Mamdani, M., 1996. Citizen and subject: contemporary Africa and the legacy of late colonialism. Princeton: Princeton University Press. 
Mamdani, M., 2002. Good Muslim, bad Muslim: a political perspective on culture and terrorism. American Anthropologist, 104 (3), 766-775.

Martin, N., and Rosello, M., 2016. Disorientation: an introduction. Culture, Theory and Critique, 57 (1), 1-16.

McMahon, M., 2009. Seeking asylum. Exchange students from Afghanistan look beyond the U.S. to Canada for safety. Think Magazine.

Melissen, J. ed., 2007. The new public diplomacy. Soft power in international relations. Houndmills: Palgrave Macmillan.

Mignolo, W., 2010. Cosmopolitanism and the de-colonial option. Studies in Philosophy and Education, 29 (2), 111127.

Mills, L., forthcoming. Post-9/11 US cultural diplomacy: the impossibility of cosmopolitanism. London: Routledge.

Opondo, S.O., 2016. Diplomacy and the colonial encounter. In: C.M. Constantinou, P. Kerr and P. Sharp, eds. The SAGE handbook of diplomacy. London: SAGE, 39-54.

Pels, P. 1997. The anthropology of colonialism: culture, history and the emergence of western governmentality. Annual review of anthropology, 26, 163-183.

Rose, N., 2007. Powers of freedom: reframing political thought. Cambridge: Cambridge University Press.

Rose, N., O'Malley, P., and Valverde, M. 2006. Governmentality. Annual review of law and social science, 2, 83-104.

US State Department. 2010. Project objectives, goals, and implementation (POGI). Kennedy-Lugar youth exchange and study (YES) program: placement components. Bureau of Educational and Cultural Affairs (ECA), Office of Citizen Exchanges, Youth Programs Division.

van der Veer, P., 2002. Colonial cosmopolitanism. In: S. Vertovec, and R. Cohen, ed. Conceiving cosmopolitanism. Oxford: Oxford University Press, 168-190.

Vrasti, W., 2013. Volunteer tourism in the global south: giving back in neoliberal times. New York: Routledge.

Walters, W., 2012. Governmentality: critical encounters. New York: Routledge.

Weber, C., 1998. Performative states. Millennium: Journal of international studies, 27, 77-95.

Woods, A. 2011. Exchange program cancelled after Afghan students flee U.S. for Canada. The Toronto Star, 13 July, 2011. Available from: http://www.thestar.com/news/canada/article/1006662.

YES Abroad. 2019a. November 2. Available from: https://twitter.com/klyesabroad/ status/1190644822090145793?s=21.

YES Abroad. 2019b. November 12. Available from: https://twitter.com/klyesabroad/status/1194283799263268865?s=21.

YES Abroad. 2019c. November 23. Available from: https://twitter.com/klyesabroad/status/1198239828187471872?s=21.

YES Abroad. 2019d. November 26. Available from: https://twitter.com/klyesabroad/status/1199432685288087560?s=21.

YES Abroad. 2019e. December 1. Available from: https://twitter.com/klyesabroad/status/1201214402135052290?s=21.

YES Abroad. 2019f. December 3. Available from: https://twitter.com/klyesabroad/status/1201939242034900998?s=21.

YES Abroad. 2019g. December 10. Available from: https://twitter.com/klyesabroad/status/1204508044127813632?s=21.

YES Abroad. 2018a. "Make the world your classroom" YES Abroad Poster. September 25. Available from: https://www.facebook.com/KLYESAbroad/photos/a. 587849624605981/2004738579583738/?type=3\&theater.

YES Abroad. 2018b. "The world is out there. Take the first step" YES Abroad Poster. September 28. Available from: https://www.facebook.com/KLYESAbroad/photos/a. 320129534711326/1176967975694140/?type=3\&theater.

YES Programs. n.d. "About us." Available from: https://www.yesprograms.org/about/ about-us.

YFU (Youth For Understanding). n.d.a. Common cultural traits in YES Program Countries. 
YFU (Youth For Understanding). n.d.b. Senegal cultural information sheet.

YFU (Youth For Understanding). n.d.c. YES resources. Available from: https://www. yfuusa.org/yes-resources.

Zemach-Bersin, T. 2009. Selling the world: study abroad marketing and the privatization of global citizenship. In: R. Lewin, ed. The handbook of practice and research in study abroad: higher education and the quest for global citizenship. London: Routledge, 303-320.

17| 17 